\title{
Pyrrole-imidazole polyamide-mediated silencing of KCNQ1OT1 expression induces cell death in Wilms' tumor cells
}

\author{
SHINSUKE YOSHIZAWA ${ }^{1}$, KYOKO FUJIWARA ${ }^{2,3}$, KIMINOBU SUGITO $^{1,3}$, SHOTA UEKUSA $^{1}$, \\ HIROYUKI KAWASHIMA ${ }^{1}$, REINA HOSHI ${ }^{1}$, YOSUKE WATANABE ${ }^{1}$, TAKAYUKI HIRANO ${ }^{1}$, \\ TAKESHI FURUYA ${ }^{1}$, TAKAYUKI MASUKO ${ }^{1}$, TAKAHIRO UENO ${ }^{3,4}$, NOBORU FUKUDA ${ }^{3,4}$, \\ MASAYOSHI SOMA ${ }^{2,3}$, TOSHINORI OZAKI ${ }^{5}$, TSUGUMICHI KOSHINAGA ${ }^{1,3}$ and HIROKI NAGASE ${ }^{6}$ \\ ${ }^{1}$ Department of Pediatric Surgery, ${ }^{2}$ Division of General Medicine, Department of Medicine, ${ }^{3}$ Innovative Therapy \\ Research Group, Nihon University Research Institute of Medical Science, and ${ }^{4}$ Division of Nephrology, \\ Hypertension and Endocrinology, Department of Medicine, Nihon University School of Medicine, Tokyo; \\ ${ }^{5}$ Laboratory of DNA Damage Signaling, and ${ }^{6}$ Laboratory of Cancer Genetics, \\ Chiba Cancer Center Research Institute, Chiba, Japan
}

Received March 5, 2015; Accepted April 8, 2015

DOI: $10.3892 /$ ijo.2015.3018

\begin{abstract}
KvDMR (an intronic $\mathrm{CpG}$ island within the $K C N Q 1$ gene) is one of the imprinting control regions on human chromosome 11p15.5. Since KvDMR exists within the promoter region of KCNQ1OT1 (antisense transcript of $K C N Q 1)$, it is likely that genomic alterations of this region including deletion, paternal uniparental disomy and de-methylation in maternal allele lead to aberrant overexpression of KCNQ1OT1. Indeed, de-methylation of KvDMR accompanied by uncontrolled overexpression of KCNQ1OT1 occurs frequently in Beckwith-Wiedemann syndrome (BWS), and around $10 \%$ of BWS patients developed embryonal tumors (Wilms' tumor or hepatoblastoma). These observations strongly suggest that silencing of KCNQ1OT1 expression might suppress its oncogenic potential. In the present study, we designed two pyrrole-imidazole (PI) polyamides, termed PI-a and PI-b, which might have the ability to bind to CCAAT boxes of the KCNQ1OT1 promoter region, and investigated their possible antitumor effect on Wilms' tumor-derived G401 cells. Gel retardation assay demonstrated that PI-a and PI-b specifically bind to their target sequences. Microscopic observations showed the efficient nuclear access of these PI polyamides. Quantitative real-time PCR analysis revealed
\end{abstract}

Correspondence to: Dr K. Fujiwara, Division of General Medicine, Department of Medicine, Nihon University School of Medicine, 30-1 Oyaguchi-Kamicho, Itabashi, Tokyo 173-8610, Japan

E-mail: fujiwara.kyoko@nihon-u.ac.jp

Professor H. Nagase, Laboratory of Cancer Genetics, Chiba Cancer Center Research Institute, 666-2 Nitona, Chuoh-ku, Chiba 260-8717, Japan

E-mail: hnagase@chiba-cc.jp

Key words: KCNQ1OT1, KvDMR, Pyrrole-imidazole polyamides, Wilms' tumor that the expression level of KCNQ1OT1 was significantly decreased when treated with PI-a and PI-b simultaneously but not with either PI-a or PI-b single treatment. Consistent with these results, the combination of PI-a and PI-b resulted in a significant reduction in viability of G401 cells in a dose-dependent manner. Furthermore, FACS analysis demonstrated that combinatory treatment with PI-a and PI-b induces cell death as compared with control cells. Taken together, our present observations strongly suggest that the combinatory treatment with PI polyamides targeting KCNQ1OT1 might be a novel therapeutic strategy to cure patients with tumors overexpressing KCNQ1OT1.

\section{Introduction}

Most autosomal genes are normally expressed from both their paternal and maternal alleles. In contrast, imprinted genes are expressed predominantly and/or exclusively from either of their paternal or maternal allele (1). For example, certain imprinted genes such as IGF2, DNMT1 and PEG3 are expressed from their paternal alleles, while their maternal alleles are silenced. Conversely, others including RB1, TP73 and $C D K N 1 C$ are expressed from their maternal alleles, whereas their paternal alleles are inactivated. Abnormal regulation of imprinting causes fetal death or development of diseases such as Beckwith-Wiedemann syndrome (BWS), Angelman syndrome and Prader-Willi syndrome.

BWS has been considered to be an overgrowth disorder accompanied by several symptoms including macrosomia, macroglossia and abdominal wall defects $(2,3)$. In addition, patients with BWS have been shown to be predisposed to childhood and embryonal tumors such as Wilms' tumor and hepatoblastoma (4-7). Majority of patients with BWS harbor aberrant alterations at human chromosome 11p15 (3). Both epigenetic and genomic alterations of the imprinting cluster within this chromosomal region have been detected in up to $80 \%$ of BWS patients as examined by currently available 
procedures $(8,9)$. The imprinting of $11 \mathrm{p} 15.5$ region was found to be regulated by two imprinting control regions, H19DMR located upstream of the $H 19$ gene and KvDMR within intron 10 of $K C N Q 1$ gene, which acts as a promoter region of its antisense gene $K C N Q 1 O T 1$ (10).

$K C N Q 1 O T 1$ encodes a paternally expressed long noncoding RNA, which has been shown to regulate imprinting of several genes present at $11 \mathrm{p} 15.5$ locus in cis $(11,12)$. Under normal conditions, the maternal and paternal alleles of KvDMR are methylated and unmethylated, respectively (10). Loss of imprinting of this region, i.e. loss of methylation of maternal allele, resulted in aberrant overexpression of KCNQ1OT1, which suppressed the circumjacent gene expression such as the $C D K N 1 C$ ( $\left.p 57^{K I P 2}\right)$ tumor suppressor gene $(13,14)$. $p 57^{K I P 2}$ is a maternally expressed imprinted gene encoding a cyclin-dependent protein kinase inhibitor implicated in the regulation of prenatal and postnatal development (15). Defects of imprinting at KvDMR account for the majority ( $50 \%)$ of molecular aberrations in BWS patients, which causes the biallelic expression of $K C N Q 1 O T 1$ and then leads to a significant suppression of $p 57^{K I P 2}$ expression $(16,17)$. Moreover, loss of methylation at KvDMR in association with reduced expression level of $p 57^{K I P 2}$ was also observed in a variety of adult tumors including colorectal cancer and lung cancer $(18,19)$. These findings indicate that silencing of KCNQ1OT1 might prohibit tumor development and/or progression.

Pyrrole-imidazole (PI) polyamide has been shown to be a novel gene-silencing small chemical compound, which binds to a minor groove of double-strand DNA in a sequence-specific manner (20). Hairpin polyamide is derived from distamycin A, which binds to AT-rich DNA sequences (21). Polyamide containing the appropriate combination of aromatic amino acids N-methylpyrrole (Py) and N-Methylimidazole (Im) binds to its target DNA with affinity and specificity comparable to that of DNA-protein interaction in cells (22). According to the previous observations, Im/Py, $\mathrm{Py} / \mathrm{Im}$ and $\mathrm{Py} / \mathrm{Py}$ pairs bind to G-C, C-G, and A-T/T-A, respectively (22).

In the present study, we have generated the PI polyamides targeting the CCAAT box, which is present at KvDMR and involved in the regulation of KCNQ1OT1 expression (10), and examined whether these compounds could specifically suppress growth of Wilms' tumor-derived G401 cells.

\section{Materials and methods}

Cell lines and culture conditions. Human fibroblasts-derived BWS6 and BWS9 cells, which have been established from Beckwith-Wiedemann syndrome patients, were kindly provided by Dr M.J. Higgins (Roswell Park Cancer Institute), and Human Wilms' tumor G401 cells were purchased from Human Science (Kyoto, Japan). Both BWS6 and BWS9 cells were maintained in DMEM (Nakarai Tesque, Kyoto, Japan) supplemented with $10 \%$ heat-inactivated fetal bovine serum (FBS) (Nichirei Bioscience, Tokyo, Japan) and $100 \mathrm{IU} / \mathrm{ml}$ of penicillin/streptomycin/glutamine (PSG) (Life Technologies, Carlsbad, CA, USA). G401 cells were cultured in McCoy's 5A (Life Technologies) supplemented with $10 \%$ heat-inactivated FBS and $100 \mathrm{IU} / \mathrm{ml}$ of PSG. Cells were grown at $37^{\circ} \mathrm{C}$ in a $\mathrm{CO}_{2}$ incubator with a humidified atmosphere containing $5 \%$ $\mathrm{CO}_{2}$ and $95 \%$ air.
Synthesis of PI polyamides targeting human KCNQ1OT1. PI polyamides used in this study were synthesized by a machine-assisted automatic synthesis system, PSSM-8 peptide synthesizer (Shimadzu, Kyoto, Japan) as previously described $(23,24)$. Two PI polyamides termed PI-a and PI-b were designed to span the boundary of 2 of 4 CCAAT boxes within human KCNQ1OT1 promoter region (Fig. 1). Mismatch PI polyamide, which does not recognize CCAAT sequence, was also designed and produced. After synthesis and purification, these PI polyamides were dissolved in ultra pure water at a final concentration of $1 \mathrm{mM}$ as stock solutions.

Gel retardation assay. FITC-labeled oligonucleotides containing target sequences of PI polyamides were synthesized by Eurofin Genomics (Tokyo, Japan). Sequences of the oligonucleotides are as follows: the oligonucleotide containing PI-a target sequence, 5'-GAGTCTAACCGGGTCGCCCTT TTGGGCGAC CCGGTTAGACTC-3' and the oligonucleotide containing PI-b target sequence, 5'-GGTGGTCGAACTAA CCCGCTTTTGCGGGTTAGTCGACCACC-3'. To generate hairpin structure of double-strand DNA, $1 \mu \mathrm{M}$ of oligonucleotides dissolved in an annealing buffer $(5 \mathrm{M} \mathrm{NaCl}, 500 \mathrm{mM}$ EDTA, $1 \mathrm{M}$ Tris- $\mathrm{HCl} \mathrm{pH} \mathrm{8.0)} \mathrm{were} \mathrm{boiled} \mathrm{at} 100^{\circ} \mathrm{C}$ for $10 \mathrm{~min}$, and then left at room temperature to gradually cool them down. The resultant FITC-labeled hairpin oligonucleotides were incubated in the presence or absence of 1 or $3 \mu \mathrm{M}$ of PI polyamides for $1 \mathrm{~h}$ at room temperature. The reaction mixtures were separated by electrophoresis through $20 \%$ polyacrylamide gel in Tris-borate-EDTA buffer and then visualized with the ImageQant LAS4000 (Fujifilm, Tokyo, Japan).

Analysis of the intracellular distribution of PI polyamides. BWS6 and G401 cells were maintained in the presence or absence of FITC-labeled PI polyamides for $24 \mathrm{~h}$. After washing in ice-cold phosphate-buffered saline (PBS, Nakarai Tesque), cells were fixed in $4 \%$ formaldehyde solution (Wako Pure Chemical Industries, Osaka, Japan) for $30 \mathrm{~min}$, and then stained with 4',6-diamidino-2-phenylindole dihydrochloride (DAPI, Sigma-Aldrich, St. Louis, MO, USA). Finally, cells were observed under fluorescence microscopy Axiovert 2000 (Carl Zeiss Microscopy, Oberkochen, Germany).

Quantitative real-time RT-PCR. Seventy-two hours after incubation in the presence or absence of PI polyamides, cells were washed in ice-cold PBS and lysed in TRIzol reagent (Life Technologies). Then, total RNA was prepared according to the manufacturer's instructions, and $500 \mathrm{ng}$ of total RNA was treated with DNaseI (Qiagen, Hilden, Germany), followed by reverse transcription using Prime Script (Takara). The resultant cDNA was subjected to quantitative real-time RT-PCR analysis using Dimer Eraser (Takara). The primers used in this analysis are as follows: KCNQ1OT1 (forward: 5'-AATGGG GATGTGAGGATCAGG-3', reverse: 5'-TGACCCCAGTG GAATATGTGC-3'); GAPDH (forward: 5'-GCACCGTCAA GGCTGAGAAC-3', reverse: 5'-TGGTGAAGACGCCAGT GGA-3'). GAPDH was used as an internal control.

Cell proliferation assay. G401 cells were seeded at $2 \times 10^{3}$ cells/96-well microplates. Then cells were exposed to the indicated concentrations of PI polyamides or left untreated. 


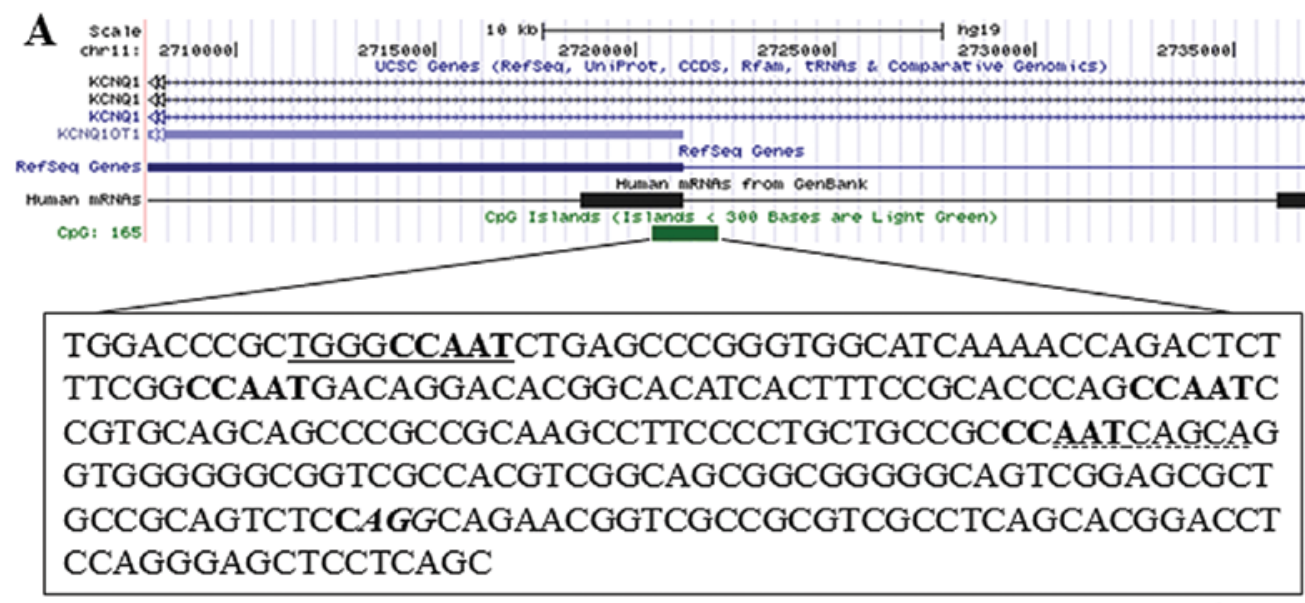

B Pl-a

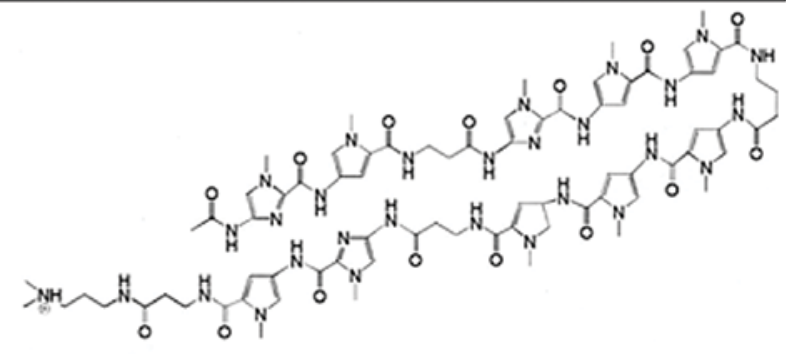

PI-b

5'-ATTGGCCCA-3' AcPyPyImIm $\beta$ PyPy $D p \beta P y P y P y \beta I m I m I m)$

3'-TAACCGGGT-5'

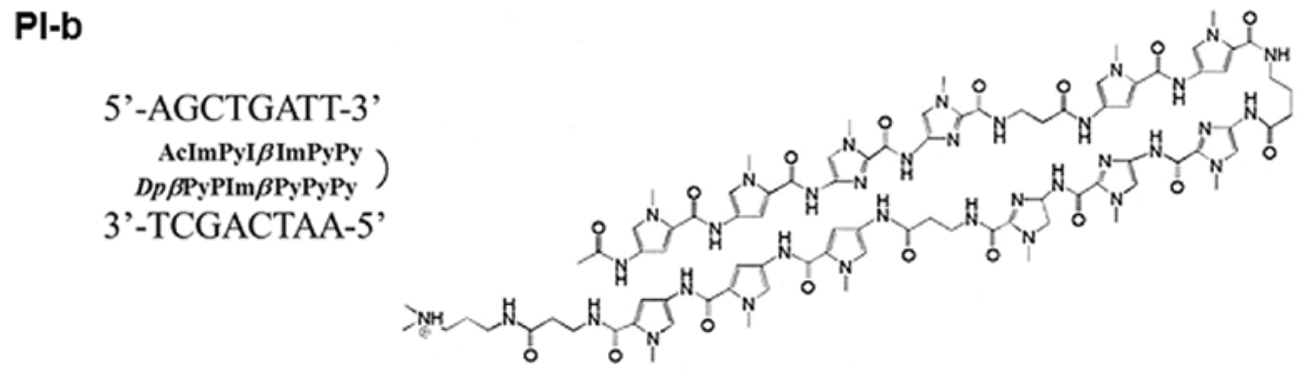

Mismatch

5'-ATTCCA-3' $\left.\begin{array}{r}\text { AcPyPy } \beta \text { PyPy } \\ D p \beta P y P y \\ \text { ImIm }\end{array}\right)$

3'-TAAGGT-5'

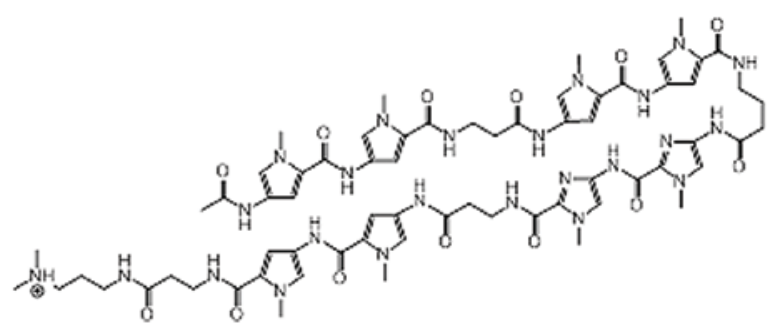

Figure 1. Promoter region of KCNQ1OT1 gene and the putative recognition sites of PI polyamides. (A) The positions of PI-a and PI-b-target sequences are underlined and dotted underlined, respectively. Four CAATT sequences and the transcription initiation site (CAG) are indicated in bold and in italic letters, respectively. (B) Chemical structure of PI polyamides (PI-a, PI-b and Mismatch) used in this study are indicated.

At the indicated time points after treatment, cell viability was measured by standard WST- 8 assay (Nacalai tesque).

Fluorescene-activated cell sorting (FACS). G401 cells were seeded at $5 \times 10^{4}$ cells $/ 2-\mathrm{cm}$ diameter dishes. Then, cells were treated with or without the indicated PI polyamides. Seventy-two hours after treatment, cells were washed in icecold PBS, treated with trypsin/EDTA, and $2 \times 10^{5}$ cells were subsequently stained with Annexin V-FITC plus propidium iodide using Annexin V-FITC Apoptosis Detection kit (Abcam, Bristol, UK) according to the manufacturer's protocols. Finally, cells were sorted by FACSCalibur flow cytometer with FL-1 (Annexin V channels) and FL-2 (PI channels), and then analyzed by CellQuest (BD Biosciences, Rockville, MD,
USA). As a positive control, cells were treated with $10 \mu \mathrm{M}$ of $\mathrm{H}_{2} \mathrm{O}_{2}$ for $9 \mathrm{~h}$ to induce cell death.

Statistical analysis. Statistical significance was calculated using the Student's t-test. Results were considered as significant with P-value of $<0.05$.

\section{Results}

Specific binding of the PI polyamides to their target doublestrand DNA. To verify whether the synthesized PI polyamides (termed PI-a and PI-b) could bind to their target DNA sequences, gel mobility shift assays were performed. For this purpose, the oligonucleotide containing target sequence of PI-a was 
$\mathbf{A}$
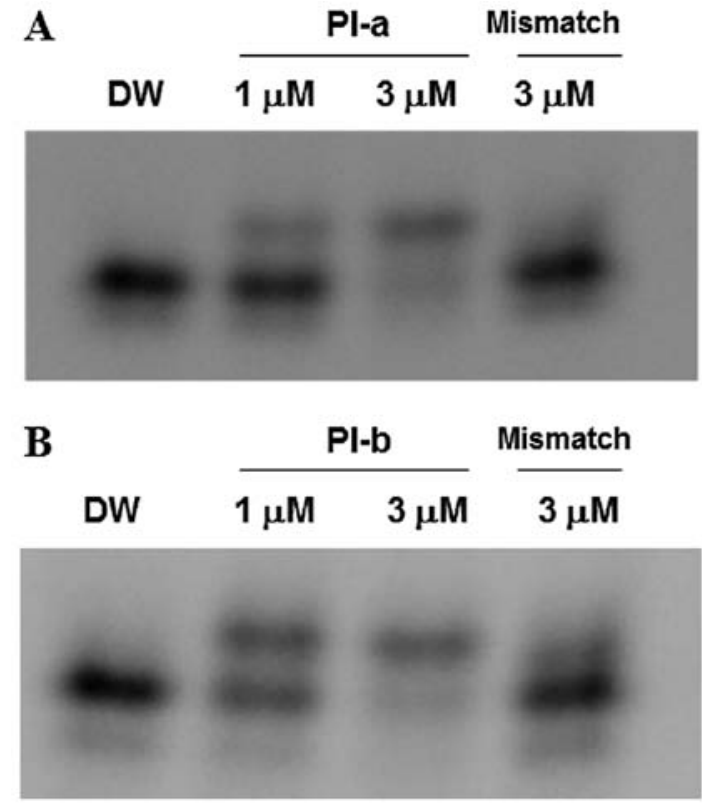

Figure 2. PI-a and PI-b specifically bind to their target DNA sequences. Gel retardation assay. FITC-labeled specific oligonucleotide was incubated with DW, PI-a or with mismatch (A), or DW, PI-b or with mismatch (B). After the incubation, the reaction mixtures were separated by polyacrylamide gel electrophoresis.

incubated with DW, PI-a or non-specific PI polyamide (termed mismatch), and then reaction mixtures were analyzed by polyacrylamide gel electrophoresis. As shown in Fig. 2A, a clearly retarded band was observed in the presence of PI-a but not of mismatch PI polyamide. Similarly, an oligonucleotide/PI-b complex was detectable in the reaction mixture containing PI-b and its target DNA sequence, whereas mismatch PI polyamide failed to bind to oligonucleotide containing the target DNA of PI-b (Fig. 2B). These results indicate that both PI-a and PI-b can specifically recognize and bind to their target DNA sequences in vitro.

Nuclear distribution of PI polyamides. Since the PI polyamides could be expected to exert gene silencing function through the direct interaction with their target DNA sequence in cells, it should be required to confirm their nuclear distribution. To adequately address this issue, we generated FITC-conjugated PI-a and PI-b. Human fibroblasts-derived from a BWS patient BWS6 cells and Wilms' tumor-derived G401 cells were cultured in fresh medium containing PI-a or PI-b. Twentyfour hours after incubation, cells were fixed, stained with DAPI and observed under a confocal microscope. As seen in Fig. 3, a significant nuclear access of FITC-labeled PI-a and PI-b was detected under our experimental conditions. These observations strongly suggest that PI-a and PI-b display nuclear localization without any drug delivery systems such as adenovirus.

Combinatory treatment with PI- $a$ and PI-b efficiently suppresses KCNQ1OT1 transcription. Next, we examined whether PI-a and/or PI-b could downregulate the transcription of their target gene KCNQ1OT1. To this end, BWS6, BWS9 and G401 cells were incubated in the presence of the indicated
$\mathbf{A}$
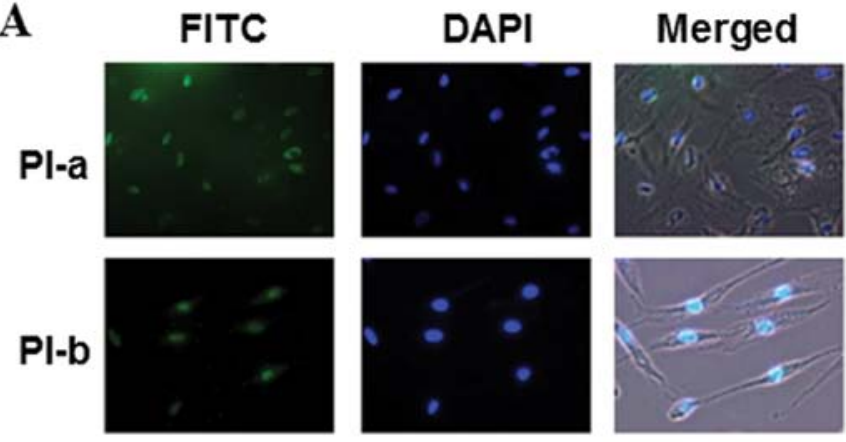

BWS6

B
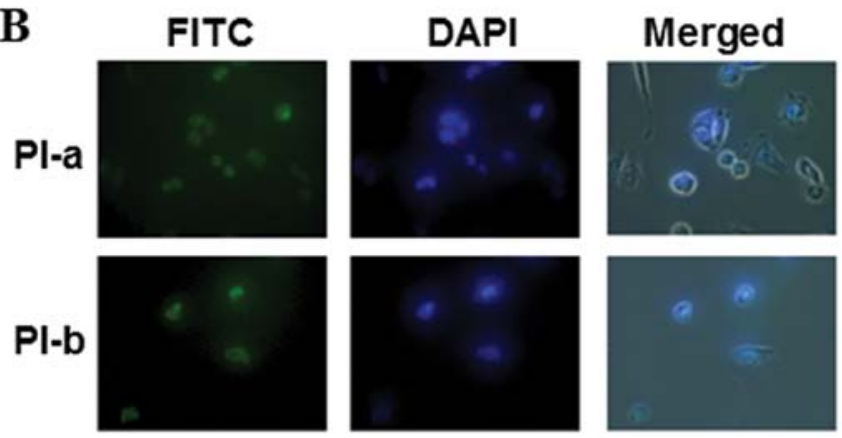

G401

Figure 3. Intracellular distribution of FITC-conjugated PI polyamides BWS-6 (A) and G401 (B) cells were incubated in the presence of FITClabeled PI-a or PI-b. After treatment, cell nuclei were stained with DAPI (blue) and observed under fluorescence microscopy. Nuclear PI polyamides emitted green color.

concentrations of PI-a, PI-b, PI-a plus PI-b or mismatch PI polyamide. Seventy-two hours after treatment, total RNA was prepared and the expression level of KCNQ1OT1 was analyzed by quantitative real-time PCR. Unexpectedly, a significant downregulation of KCNQ1OT1 was not detected in all cells examined after PI-a or PI-b single treatment (Fig. 4). Notably, the combinatory treatment of cells with PI-a and PI-b resulted in a marked decrease in the expression level of KCNQ1OT1. As expected, mismatch PI polyamide alone had no detectable effect on the expression level of KCNQ1OT1.

Reduction in cell viability of G401 cells exposed to a combined treatment with PI- $a$ and PI- $b$. Since it has been described that a higher KCNQ1OT1 level is tightly associated with tumor cell growth (25), these observations prompted us to examine whether the simultaneous treatment of PI-a and PI-b could affect cell proliferation of G401 cells. For this purpose, G401 cells were exposed to the indicated concentrations of PI-a plus PI-b or mismatch PI polyamide. At the indicated time points after treatment, cells were subjected to the standard WST8 assay to assess their cell viability. As shown in Fig. 5, the combinatory treatment of PI-a and PI-b caused a remarkable suppression of G401 cell proliferation, whereas mismatch PI polyamide had a negligible effect on their viability. As expected, PI-a or PI-b single treatment did not affect G401 cell proliferation (data not shown). These results imply that the PI polyamide-mediated silencing of KCNQ1OT1 expression might contribute to the suppression of G401 cell proliferation. 

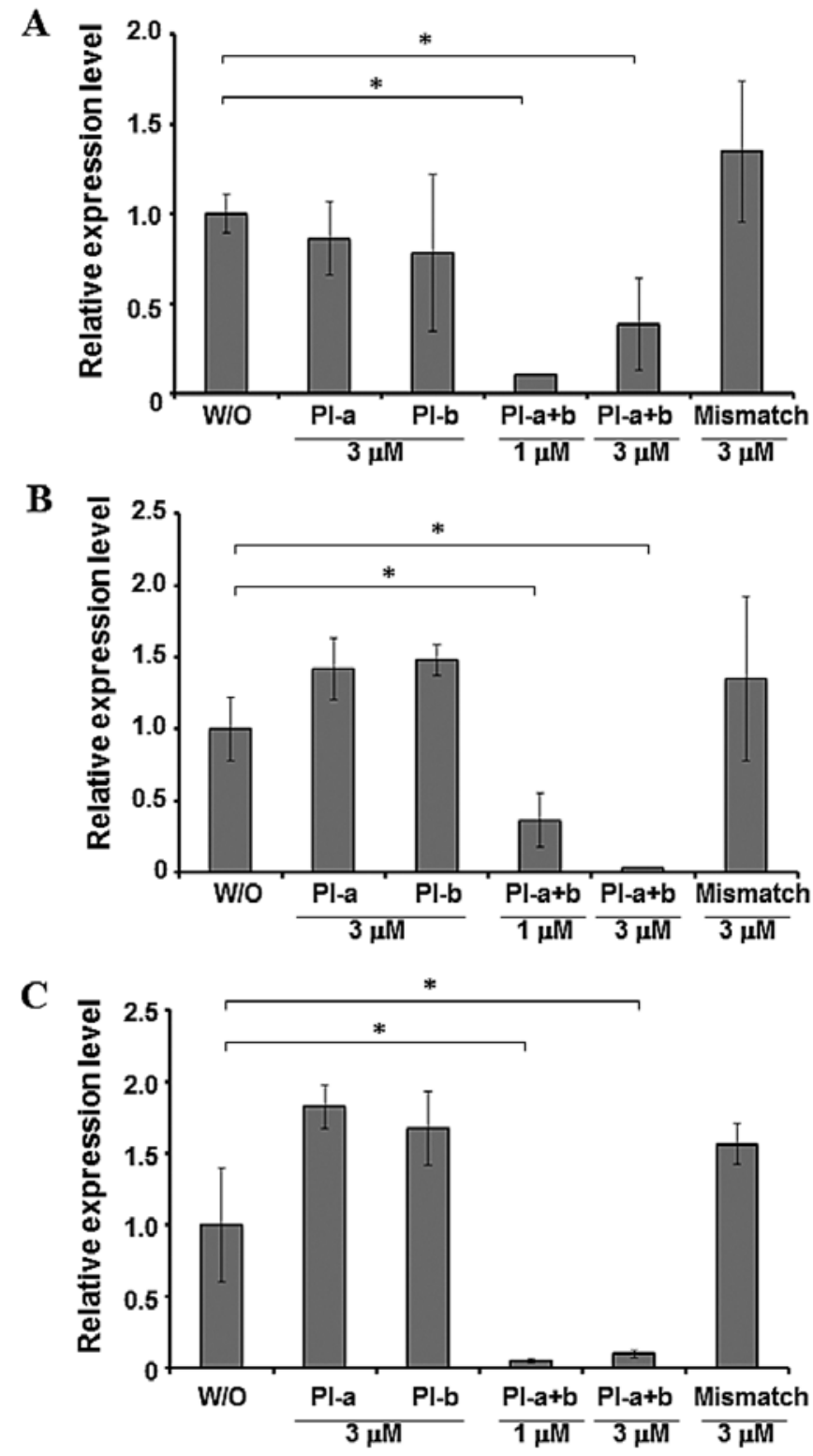

Figure 4. Expression level of KCNQ1OT1 in cells treated with PI-a, PI-b or PI-a plus PI-b. BWS-6 (A), BWS-9 (B) or G401 (C) cells were exposed to the indicated concentrations of PI polyamide (PI-a, PI-b or PI-a plus PI-b) or left untreated. Seventy-two hours after treatment, total RNA was prepared from these cells and the expression level of KCNQ1OT1 was examined by quantitative real-time RT-PCR. ${ }^{*} \mathrm{P}<0.001$.

G401 cells undergo cell death in response to PI-a plus PI-b. Based on our above-mentioned results, we asked whether a combined treatment with PI-a plus PI-b in G401 cells could induce cell death. To this end, we used PI and Annexin V double staining experiments followed by FACS analysis. It has been established that Annexin V-positive cells undergo early apoptotic cell death (26). G401 cells were treated with the indicated concentrations of PI-a plus PI-b or with mismatch PI polyamide. As a positive control, G401 cells were exposed to $\mathrm{H}_{2} \mathrm{O}_{2}$ for $9 \mathrm{~h}$. It is well-known that Annexin V-positive/ PI-negative cells and Annexin V-positive/PI-positive cells undergo early apoptosis and late apoptosis/necrosis, respectively (27). As seen in Fig. 6A, a large number of cells exposed to $\mathrm{H}_{2} \mathrm{O}_{2}$ displayed Annexin V-positive/PI-positive, indicating that cells undergo late apoptosis in response to $\mathrm{H}_{2} \mathrm{O}_{2}$. Apoptotic

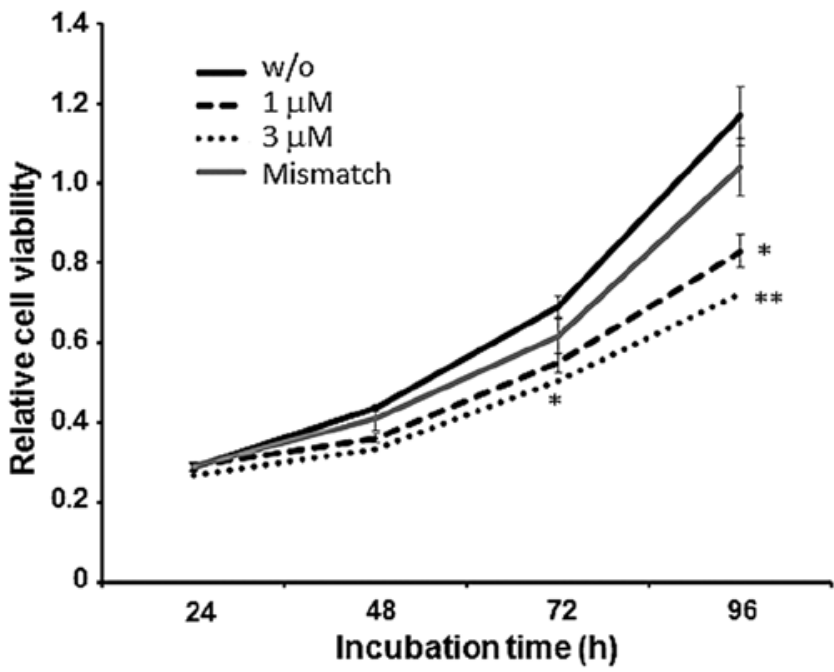

Figure 5. Reduction of cell viability of G401 cells treated with PI-a plus PI-b. G401 cells were exposed to the indicated concentrations of PI-a and PI-b, mismatch or left untreated. At the indicated time periods after treatment, cell viability was measured by standard WST 8 assay. ${ }^{*} \mathrm{P}<0.01,{ }^{* *} \mathrm{P}<0.001$.

cells were barely detectable in untreated or mismatch-treated cells. In contrast, substantial amounts of cells were enriched in early and late apoptotic fractions. Average number of cells showing early apoptosis, late apoptosis or necrosis is depicted as a graph in Fig. 6B. According to our present results, the combinatory treatment of cells with PI-a and PI-b markedly induced apoptosis in a dose-dependent manner. In addition, the relatively small number of Annexin V-negative/PI-positive cells was observed in each experiment.

\section{Discussion}

In the present study, we successfully produced pyrroleimidazole (PI) polyamides (PI-a and PI-b) against CCAAT boxes within the promoter region of oncogenic KCNQ1OT1 gene. Based on our present results, the combined treatment with PI-a and PI-b in Wilms' tumor-derived G401 cells significantly reduced $K C N Q 1 O T 1$ gene expression and also their cell viability, which might be caused by the induction of apoptosis.

The molecular targeting anticancer drugs, which could block oncogenic signaling pathways, would be powerful and promising cancer therapeutics. Recent high-throughput technologies make it much easier to identify critical genes implicated in the initiation and/or progression of a variety of cancers, which are aberrantly expressed and/or activated in cancer cells (28). Although several antisense oligo DNA and siRNA against these cancer-related specific genes have been developed, their poor cellular uptake and also delivery to the appropriate organs or tissues remain major obstacles for their clinical application (29). Since it has been shown that PI polyamides are efficiently localized into cell nucleus without any specific drug delivery systems such as virus vehicles both in vitro and in vivo $(30,31)$, these observations prompted us to develop gene-specific silencing PI polyamides. For example, we have previously described that PI polyamide recognizing AP-1-binding site located within the promoter region of matrix metalloproteinase (MMP)-9 gene massively reduces 
A w/O treatment

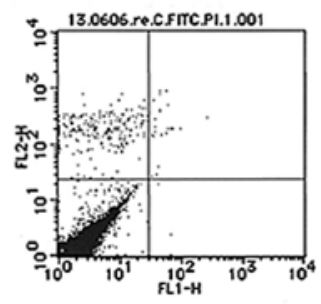

Positive Control

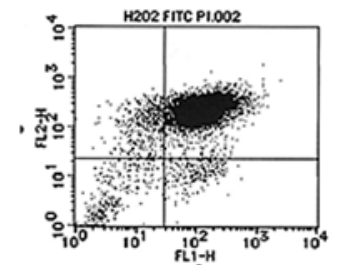

B

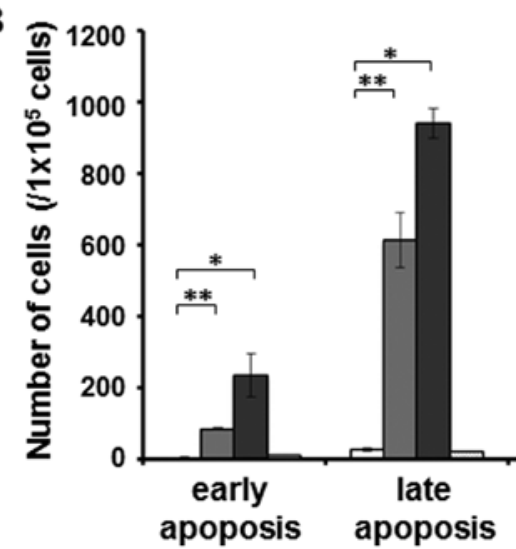

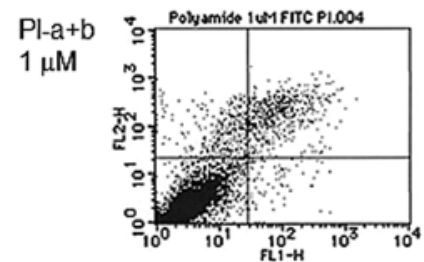

$\mathrm{Pl}-\mathrm{a}+\mathrm{b}$ $3 \mu \mathrm{M}$
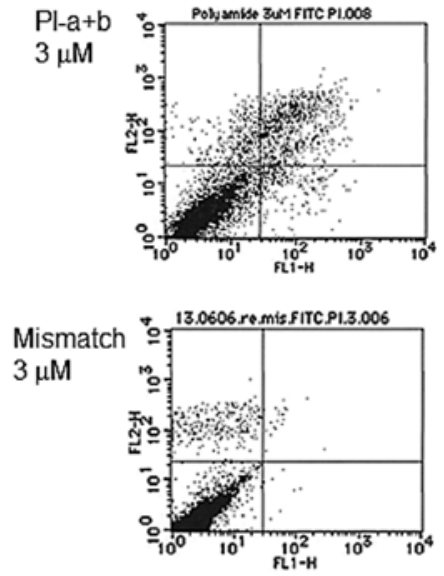

Qno treat

$\square \mathrm{Pl}-\mathrm{a}+\mathrm{b} 1 \mu \mathrm{M}$

- $\mathrm{Pl}-\mathrm{a}+\mathrm{b} 3 \mu \mathrm{M}$

amismatch $3 \mu \mathrm{M}$

Figure 6. Induction of cell death by combined treatment with PI-a and PI-b. G401 cells were exposed to the indicated concentrations of PI-a and PI-b, mismatch or left untreated. (A) Seventy-two hours after treatment, cells were stained with FITC-labeled Annexin V and PI, and then analyzed by FACS. Representative FACS images are shown. (B) Number of cells undergoing early apoptosis (Annexin V-positive/PI-negative) and late apoptosis (Annexin V-positive/PI-positive) were measured. ${ }^{*} \mathrm{P}<0.05,{ }^{* *} \mathrm{P}<0.01$

its expression level and also inhibits malignant phenotypes of cancer cells both in vitro and in vivo (30).

In our results, single application of either PI-a or PI-b did not affect the expression level of KCNQ1OT1, however, the treatment with the combination of these two PI polyamides downregulated KCNQ1OT1. At the present moment, we could not find good explanation for this discrepancy. Previously, Du et al reported that an introduced point mutation in each of four CCAAT box sequences reduced promoter activity modestly but not completely $(10,32)$. The authors also showed data suggesting that simultaneous targeting of two CCAAT box regions of KCNQ1OT1 promoter could be also involved in the transcriptional regulation of this gene. Those findings indicate that blocking just one CCAAT box is not enough to suppress the gene expression level.

Of note, we found for the first time that the combinatory treatment of our PI polyamides significantly downregulates oncogenic KCNQ1OT1 gene transcription, and its downregulation leads to the suppression of cancerous cell proliferation as well as the induction of apoptosis. It has been shown that $K C N Q 1 O T 1$ has the ability to regulate the imprinting status of the circumjacent genes, such as ASCL2, TSPAN32,

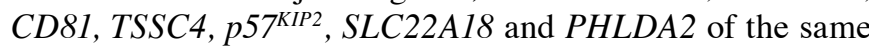
allele $(13,33)$. Among them, $p 57^{K I P 2}$ has been considered to be one of tumor suppressor gene products implicated in BWS (34). Accumulating evidence suggests that $\mathrm{p} 57^{\mathrm{KIP} 2}$ is one of Cip/Kip family of cyclin-dependent protein kinase inhibitor and blocks cell proliferation by inhibiting cell cycle progression (35). Additionally, $\mathrm{p} 57^{\mathrm{KIP} 2}$ has the ability to promote apoptosis and prohibit tissue invasion as well as metastasis $(36,37)$. Therefore, we sought to examine whether the combinatory treatment of the PI polyamides could affect the expression level of the above-mentioned circumjacent genes including $p 57^{K I P 2}$. Unexpectedly, the expression level of these genes remained unchanged even in the presence of the PI polyamides (data not shown). At present, we do not know how the combined treatment with the two PI polyamides could suppress cancerous cell proliferation and also induce apoptosis. Further study is required to adequately address this issue.

Collectively, our present results indicate that the above reported PI polyamides targeting KCNQ1OT1 promotes apoptosis in Wilms' tumor G401 cells through a significant downregulation of $K C N Q 1 O T 1$ transcription, and support our hypothesis that PI polyamide-mediated gene silencing might be a novel attractive strategy for anticancer therapy.

\section{Acknowledgements}

This work was supported by the Academic Frontier Project for 2006 Project for Private Universities, a matching fund subsidy from MEXT (to H.N.), and MEXT-Supported Program for 
the Strategic Research Foundation at Private Universities (2011-2015) to K.F., K.S., T.U., N.F., M.S., T.K., and H.N.

\section{References}

1. Reik W and Walter J: Genomic imprinting: Parental influence on the genome. Nat Rev Genet 2: 21-32, 2001.

2. Choufani S, Shuman C and Weksberg R: Beckwith-Wiedemann syndrome. Am J Med Genet C Semin Med Genet 154C: 343-354, 2010.

3. Jacob KJ, Robinson WP and Lefebvre L: Beckwith-Wiedemann and Silver-Russell syndromes: Opposite developmental imbalances in imprinted regulators of placental function and embryonic growth. Clin Genet 84: 326-334, 2013.

4. Weksberg R, Nishikawa J, Caluseriu O, Fei YL, Shuman C, Wei C, Steele L, Cameron J, Smith A, Ambus I, et al: Tumor development in the Beckwith-Wiedemann syndrome is associated with a variety of constitutional molecular $11 \mathrm{p} 15$ alterations including imprinting defects of KCNQ1OT1. Hum Mol Genet 10 : 2989-3000, 2001.

5. DeBaun MR and Tucker MA: Risk of cancer during the first four years of life in children from The Beckwith-Wiedemann Syndrome Registry. J Pediatr 132: 398-400, 1998.

6. Rump P, Zeegers MP and van Essen AJ: Tumor risk in BeckwithWiedemann syndrome: A review and meta-analysis. Am J Med Genet A 136: 95-104, 2005.

7. Higashimoto K, Soejima H, Saito T, Okumura K and Mukai T: Imprinting disruption of the CDKN1C/KCNQ1OT1 domain: The molecular mechanisms causing Beckwith-Wiedemann syndrome and cancer. Cytogenet Genome Res 113: 306-312, 2006.

8. Scott RH, Douglas J, Baskcomb L, Nygren AO, Birch JM Cole TR, Cormier-Daire V, Eastwood DM, Garcia-Minaur S, Lupunzina $\mathrm{P}$, et al: Methylation-specific multiplex ligationdependent probe amplification (MS-MLPA) robustly detects and distinguishes $11 \mathrm{p} 15$ abnormalities associated with overgrowth and growth retardation. J Med Genet 45: 106-113, 2008.

9. Weksberg R, Shuman C and Beckwith JB: Beckwith-Wiedemann syndrome. Eur J Hum Genet 18: 8-14, 2010.

10. Du M, Zhou W, Beatty LG, Weksberg R and Sadowski PD: The KCNQ1OT1 promoter, a key regulator of genomic imprinting in human chromosome 11p15.5. Genomics 84: 288-300, 2004.

11. Kanduri C: Kcnq1ot1: A chromatin regulatory RNA. Semin Cell Dev Biol 22: 343-350, 2011

12. Mohammad F, Pandey GK, Mondal T, Enroth S, Redrup L, Gyllensten U and Kanduri C: Long noncoding RNA-mediated maintenance of DNA methylation and transcriptional gene silencing. Development 139: 2792-2803, 2012.

13. Mancini-Dinardo D, Steele SJ, Levorse JM, Ingram RS and Tilghman SM: Elongation of the Kcnqlot1 transcript is required for genomic imprinting of neighboring genes. Genes Dev 20: 1268-1282, 2006.

14. Chiesa N, De Crescenzo A, Mishra K, Perone L, Carella M, Palumbo O, Mussa A, Sparago A, Cerrato F, Russo S, et al: The KCNQ1OT1 imprinting control region and non-coding RNA: New properties derived from the study of Beckwith-Wiedemann syndrome and Silver-Russell syndrome cases. Hum Mol Genet 21: $10-25,2012$.

15. Zhang P, Wong C, DePinho RA, Harper JW and Elledge SJ: Cooperation between the Cdk inhibitors p27(KIP1) and p57(KIP2) in the control of tissue growth and development. Genes Dev 12: 3162-3167, 1998.

16. Lee MP, DeBaun MR, Mitsuya K, Galonek HL, Brandenburg S, Oshimura $\mathrm{M}$ and Feinberg AP: Loss of imprinting of a paternally expressed transcript, with antisense orientation to KVLQT1, occurs frequently in Beckwith-Wiedemann syndrome and is independent of insulin-like growth factor II imprinting. Proc Natl Acad Sci USA 96: 5203-5208, 1999.

17. Diaz-Meyer N, Day CD, Khatod K, Maher ER, Cooper W, Reik W, Junien C, Graham G, Algar E, Der Kaloustian VM, et al: Silencing of CDKN1C (p57KIP2) is associated with hypomethylation at KvDMR1 in Beckwith-Wiedemann syndrome. J Med Genet 40: 797-801, 2003.

18. Nakano S, Murakami K, Meguro M, Soejima H, Higashimoto K, Urano T, Kugoh H, Mukai T, Ikeguchi M and Oshimura M: Expression profile of LIT1/KCNQ1OT1 and epigenetic status at the KvDMR1 in colorectal cancers. Cancer Sci 97: 1147-1154, 2006.
19. Soejima H, Nakagawachi T, Zhao W, Higashimoto $K$, Urano T, Matsukura S, Kitajima Y, Takeuchi M, Nakayama M, Oshimura M, et al: Silencing of imprinted CDKN1C gene expression is associated with loss of $\mathrm{CpG}$ and histone $\mathrm{H} 3$ lysine 9 methylation at DMR-LIT1 in esophageal cancer. Oncogene 23: 4380-4388, 2004.

20. Dervan PB: Molecular recognition of DNA by small molecules. Bioorg Med Chem 9: 2215-2235, 2001.

21. Arcamone F, Penco S and Orezzi P, Nicolella V and Pirelli A: Structure and synthesis of distamycin A. Nature 203: 1064-1065, 1964.

22. Dervan PB and Edelson BS: Recognition of the DNA minor groove by pyrrole-imidazole polyamides. Curr Opin Struct Biol 13: 284-299, 2003

23. Bando T, Narita A, Saito I and Sugiyama H: Molecular design of a pyrrole-imidazole hairpin polyamides for effective DNA alkylation. Chemistry 8: 4781-4790, 2002.

24. Murty MS and Sugiyama H: Biology of N-methylpyrrole$\mathrm{N}$-methylimidazole hairpin polyamide. Biol Pharm Bull 27: 468-474, 2004.

25. Wan J, Huang M, Zhao H, Wang C, Zhao X, Jiang X, Bian S, $\mathrm{He} \mathrm{Y}$ and Gao Y: A novel tetranucleotide repeat polymorphism within KCNQ1OT1 confers risk for hepatocellular carcinoma. DNA Cell Biol 32: 628-634, 2013.

26. Vermes I, Haanen C, Steffens-Nakken H and Reutelingsperger C: A novel assay for apoptosis. Flow cytometric detection of phosphatidylserine expression on early apoptotic cells using fluorescein labelled Annexin V. J Immunol Methods 184: 39-51, 1995.

27. Aubry JP, Blaecke A, Lecoanet-Henchoz S, Jeannin P, Herbault N, Caron G, Moine V and Bonnefoy JY: Annexin V used for measuring apoptosis in the early events of cellular cytotoxicity. Cytometry 37: 197-204, 1999.

28. Dobbelstein M and Moll U: Targeting tumour-supportive cellular machineries in anticancer drug development. Nat Rev Drug Discov 13: 179-196, 2014

29. Farooqi AA, Rehman ZU and Muntane J: Antisense therapeutics in oncology: Current status. Onco Targets Ther 7: 2035-2042, 2014.

30. Wang X, Nagase H, Watanabe T, Nobusue H, Suzuki T, Asami Y, Shinojima Y, Kawashima H, Takagi K, Mishra R, et al: Inhibition of MMP-9 transcription and suppression of tumor metastasis by pyrrole-imidazole polyamide. Cancer Sci 101: 759-766, 2010.

31. Matsuda H, Fukuda N, Ueno T, Katakawa M, Wang X, Watanabe T, Matsui S, Aoyama T, Saito K, Bando T, et al: Transcriptional inhibition of progressive renal disease by gene silencing pyrrole-imidazole polyamide targeting of the transforming growth factor- $\beta 1$ promoter. Kidney Int 79 : 46-56, 2011

32. Du M, Beatty LG, Zhou W, Lew J, Schoenherr C, Weksberg R and Sadowski PD: Insulator and silencer sequences in the imprinted region of human chromosome 11p15.5. Hum Mol Genet 12: 1927-1939, 2003

33. Fitzpatrick GV, Soloway PD and Higgins MJ: Regional loss of imprinting and growth deficiency in mice with a targeted deletion of KvDMR1. Nat Genet 32: 426-431, 2002.

34. Arima T, Kamikihara T, Hayashida T, Kato K, Inoue $\mathrm{T}$, Shirayoshi Y, Oshimura M, Soejima H, Mukai T and Wake N: ZAC, LIT1 (KCNQ1OT1) and p57KIP2 (CDKN1C) are in an imprinted gene network that may play a role in BeckwithWiedemann syndrome. Nucleic Acids Res 33: 2650-2660, 2005.

35. LaBaer J, Garrett MD, Stevenson LF, Slingerland JM, Sandhu C, Chou HS, Fattaey A and Harlow E: New functional activities for the p21 family of CDK inhibitors. Genes Dev 11: 847-862, 1997.

36. Jin RJ, Lho Y, Wang Y, Ao M, Revelo MP, Hayward SW, Wills ML, Logan SK, Zhang P and Matusik RJ: Down-regulation of p57Kip2 induces prostate cancer in the mouse. Cancer Res 68: 3601-3608, 2008.

37. Guo H, Lv Y, Tian T, Hu TH, Wang WJ, Sui X, Jiang L, Ruan ZP and Nan KJ: Downregulation of p57 accelerates the growth and invasion of hepatocellular carcinoma. Carcinogenesis 32: 1897-1904, 2011 